ARTICLE

\title{
Electrochemical oxygen reduction catalysed by $\mathrm{Ni}_{3}$ (hexaiminotriphenylene) 2
}

Elise M. Miner', Tomohiro Fukushima', Dennis Sheberla, Lei Sun ${ }^{1}$, Yogesh Surendranath ${ }^{1}$ \& Mircea Dincă

Control over the architectural and electronic properties of heterogeneous catalysts poses a major obstacle in the targeted design of active and stable non-platinum group metal electrocatalysts for the oxygen reduction reaction. Here we introduce $\mathrm{Ni}_{3}(\mathrm{HITP})_{2}$ $(\mathrm{HITP}=2,3,6,7,10,11$-hexaiminotriphenylene $)$ as an intrinsically conductive metal-organic framework which functions as a well-defined, tunable oxygen reduction electrocatalyst in alkaline solution. $\mathrm{Ni}_{3}(\mathrm{HITP})_{2}$ exhibits oxygen reduction activity competitive with the most active non-platinum group metal electrocatalysts and stability during extended polarization. The square planar $\mathrm{Ni}-\mathrm{N}_{4}$ sites are structurally reminiscent of the highly active and widely studied non-platinum group metal electrocatalysts containing $\mathrm{M}-\mathrm{N}_{4}$ units. $\mathrm{Ni}_{3}(\mathrm{HITP})_{2}$ and analogues thereof combine the high crystallinity of metal-organic frameworks, the physical durability and electrical conductivity of graphitic materials, and the diverse yet well-controlled synthetic accessibility of molecular species. Such properties may enable the targeted synthesis and systematic optimization of oxygen reduction electrocatalysts as components of fuel cells and electrolysers for renewable energy applications.

\footnotetext{
${ }^{1}$ Department of Chemistry, Massachusetts Institute of Technology, 77 Massachusetts Avenue, Cambridge, Massachusetts 02139, USA. Correspondence and requests for materials should be addressed to M.D. (email: mdinca@mit.edu).
} 
$\mathrm{T}$ he development of heterogeneous oxygen reduction reaction (ORR) electrocatalysts for implementation into fuel cell and electrolyser cathodes is a major research thrust in the arena of renewable fuel development. Achieving desired architectural and electronic properties of such catalysts remains difficult, however, because several variables must be optimized simultaneously, requiring synthetic tunability that is rarely available in the solid state. Desirable characteristics of an ORR electrocatalyst include: high active site density, reproducible synthesis and catalytic activity, stability in the electrolyte and in oxygen and peroxide, and low overpotential relative to the thermodynamic $4 \mathrm{e}^{-}$oxygen-to-water reduction potential of $1.23 \mathrm{~V}$ (versus the reversible hydrogen electrode, RHE). One structural motif that has proven successful in catalysing ORR with high activity and physical robustness is the M- $\mathrm{N}_{x}$ unit, where $\mathrm{M}=\mathrm{a}$ non-platinum group metal (for example, $\mathrm{Fe}, \mathrm{Co}$, $\mathrm{Ni}, \mathrm{Cu}$ ) chelated in a nitrogenous environment. These structures were popularized after the 1964 report by Jasinski ${ }^{1}$ that detailed the high ORR activity of cobalt phthalocyanine complexes blended with electrically conductive acetylene black. The ability for oxygen to chemisorb onto these $M-\mathrm{N}_{x}$ sites without degrading the material fuelled extensive investigations of ORR on $\mathrm{M}$ - $\mathrm{N}_{x}$-containing catalysts ${ }^{2-5}$. Though active towards ORR, M- $\mathrm{N}_{x}$ complexes have shown inconsistent stability in various electrolytes, motivating high-temperature treatment of the materials to enhance catalyst longevity and electrical conductivity ${ }^{3,5}$. Thermal treatment indeed increased the stability of the materials, but introduced new challenges in maintaining synthetic control over structure formation, identifying the catalytic active sites, and establishing structurefunction relationships useful for catalyst optimization and mechanistic understanding. Thus, the search for active, intrinsically conductive, and chemically and electrochemically stable ORR electrocatalysts possessing well-defined and tunable active sites continues.

One class of materials that could answer these challenges is metal-organic frameworks (MOFs). These materials are compelling choices for electrocatalytic applications because their high surface area maximizes active site density, and their tunable chemical structure affords tailor-made microenvironments for controllable reaction conditions within the pores. Despite their promising features, MOFs have rarely been used for electrocatalytic applications because they are typically electrical insulators $^{6-11}$. Recently, synthetic advances have given rise to conductive MOFs, some of which exhibit encouraging properties as electrocatalysts ${ }^{12-16}$, but to our knowledge none have been experimentally shown to mediate ORR electrocatalysis.

Here we introduce $\mathrm{Ni}_{3}(\mathrm{HITP})_{2}(\mathrm{HITP}=2,3,6,7,10$, 11-hexaiminotriphenylene), a conductive two-dimensionally layered material structurally reminiscent of the long-studied $\mathrm{M}-\mathrm{N}_{x}$ ORR electrocatalysts (Fig. 1$)^{17}$, as a representative of a new class of highly ordered ORR electrocatalysts exhibiting ORR activity and electrical conductivity $\left(\sigma=40 \mathrm{~S} \mathrm{~cm}^{-1}\right)^{17}$ with no post-synthetic treatment or modification. In addition to possessing ORR activity competitive with the most active nonplatinum group metal (nPGM) electrocatalysts to date, $\mathrm{Ni}_{3}(\mathrm{HITP})_{2}$ retains $88 \%$ of its current density and undergoes no visible morphological degradation during prolonged electrochemical cycling. This study highlights conductive MOFs as a powerful platform for the development of tunable, designer electrocatalysts. It is noted that MOFs have been used as scaffolds for ORR electrocatalysts formed from high-temperature $\left(>600^{\circ} \mathrm{C}\right)$ pyrolysis ${ }^{18-37}$ as well as incorporated into composites containing graphene oxide and porphyrin additives $^{7,8}$. Whereas such materials indeed exhibit competitive ORR activity, the pyrolysis involved in their preparation eliminates the crystallinity and synthetic control inherent to MOFs. Our aim herein is to introduce a multi-faceted handle on imposing in a controlled manner structural, chemical and electronic properties on our material for reaction-targeted, MOF-based electrocatalyst design.

\section{Results}

Synthesis and quantification of $\mathrm{Ni}_{3}(\mathrm{HITP})_{2} \cdot \mathrm{Ni}_{3}(\mathrm{HITP})_{2}$ can be grown solvothermally as a thin film on a variety of electrode surfaces using synthetic conditions mimicking those employed for the synthesis of bulk material ${ }^{17}$. Glassy carbon disk electrodes $(5 \mathrm{~mm}$ diameter) served as the working electrodes for all investigations described herein unless otherwise noted, and all potentials are referenced to RHE. Deposition of $\mathrm{Ni}_{3}(\mathrm{HITP})_{2}$ onto the glassy carbon electrodes typically afforded loadings of $\sim 5 \mu \mathrm{g}$ of MOF. The loadings were determined precisely in each case by atomic absorption spectroscopy (AAS) and verified by inductively coupled plasma-mass spectrometric (ICP-MS) measurements. The thickness of the film was analysed by atomic force microscopy. $\mathrm{Ni}_{3}(\mathrm{HITP})_{2}$ films grown on glassy carbon electrodes have a thickness of $\sim 120 \mathrm{~nm}$, whereas films grown on indium tin oxide exhibit a similar morphology with a thickness of $\sim 300 \mathrm{~nm}$ (Supplementary Fig. 1).

ORR activity of $\mathrm{Ni}_{3}(\mathrm{HITP})_{2}$. Cyclic voltammograms of $\mathrm{Ni}_{3}(\mathrm{HITP})_{2}$ thin films on glassy carbon rotating disk electrodes recorded in the absence of $\mathrm{O}_{2}$ revealed a significant double layer capacitance that increased with increasing scan rate (Supplementary Fig. 2), reflecting the high surface area of the modified electrodes ${ }^{38}$. Indeed, $\mathrm{Ni}_{3}(\mathrm{HITP})_{2}$ exhibits a BrunauerEmmett-Teller-specific surface area of $629.9 \pm 0.7 \mathrm{~m}^{2} \mathrm{~g}^{-1}$, as calculated from its nitrogen adsorption isotherm (Supplementary Fig. 3). Under $\mathrm{O}_{2}$ atmosphere, the material reduces oxygen with an onset potential $\left(j=-50 \mu \mathrm{Acm}^{-2}\right)$ of $0.82 \mathrm{~V}$ in a $0.10 \mathrm{M}$ aqueous solution of $\mathrm{KOH}(\mathrm{pH}=13.0$; Fig. 2). The measured ORR onset potential is competitive with the most active nPGM ORR electrocatalysts reported thus $\mathrm{far}^{39}$ and sits at an overpotential of $0.18 \mathrm{~V}$ relative to $\mathrm{Pt}\left(E_{\text {onset }}=1.00 \mathrm{~V}\right)$.

Notably, cyclic voltammetry of the film on indium tin oxide electrodes shows the same ORR activity as the films on the glassy carbon electrodes (Supplementary Fig. 4), verifying that the MOF does not simply enhance the ORR activity of the glassy carbon electrode but rather acts as a stand-alone ORR electrocatalyst regardless of the substrate.

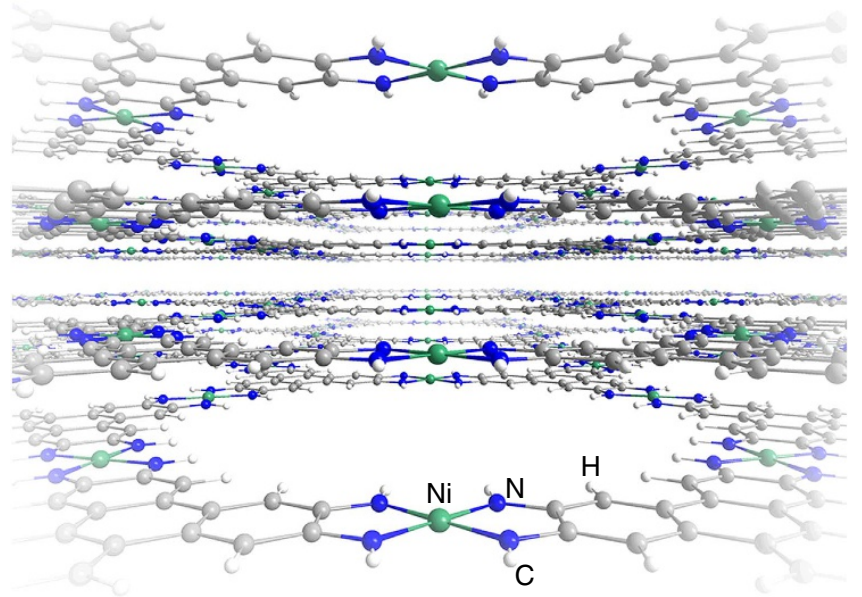

Figure $\mathbf{1} \mid \mathbf{N i}_{\mathbf{3}}(\mathbf{H I T P})_{\mathbf{2}}$ structure. Perspective view of the two-dimensional layered structure of $\mathrm{Ni}_{3}(\mathrm{HITP})_{2}$ (ref. 17). 


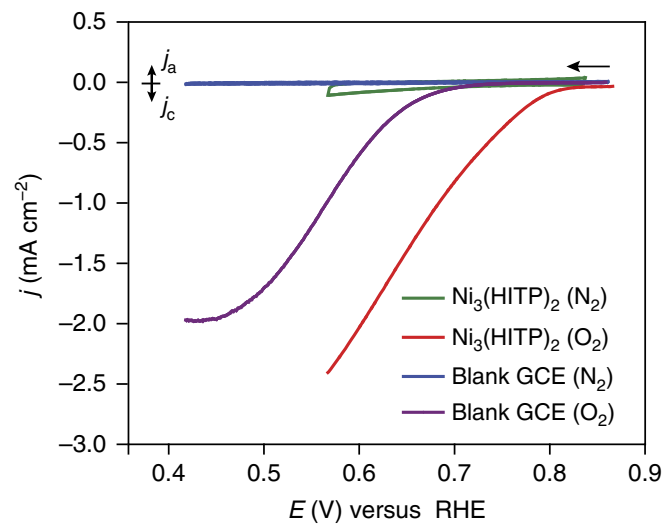

Figure 2 | ORR performance. Polarization curves of $\mathrm{Ni}_{3}(\mathrm{HITP})_{2}$ under $\mathrm{N}_{2}$ (green) versus $\mathrm{O}_{2}$ atmosphere (red) as well as of the blank glassy carbon electrode under $\mathrm{N}_{2}$ versus $\mathrm{O}_{2}$ atmosphere (blue and purple, respectively). Scan rate $=5 \mathrm{mVs}^{-1}$, rotation rate $=2,000$ r.p.m., electrolyte $=0.10 \mathrm{M}$ aqueous $\mathrm{KOH}$, counter electrode $=\mathrm{Pt}$ mesh, reference electrode $=\mathrm{Hg} / \mathrm{HgO}$ $(1.00 \mathrm{M} \mathrm{KOH})$, working electrode = glassy carbon electrode $(\mathrm{GCE})$.

Stability of $\mathrm{Ni}_{3}(\mathrm{HITP})_{2}$ during ORR. Steady-state potentiostatic measurements at $E=0.77 \mathrm{~V}$ showed that $88 \%$ of the initial current density is retained over $8 \mathrm{~h}$ (Supplementary Fig. 5), in-line with other nPGM ORR catalysts ${ }^{5,40-44}$. Cyclic voltammetry of the modified electrode after the durability study showed no shift in the diffusion-limited region of the polarization curve, indicating that any alterations to the material during electrocatalysis were not significant enough to decrease the mass transport properties of the $\mathrm{Ni}_{3}(\mathrm{HITP})_{2}$ film (Supplementary Fig. 6). Moreover, cyclic voltammetry of the electrolyte after these $8 \mathrm{~h}$, using a fresh unmodified glassy carbon electrode, indicated no leaching from the $\mathrm{Ni}_{3}(\mathrm{HITP})_{2}$ films, evidencing the heterogeneous nature of the catalyst. Additionally, ICP-MS and AAS analyses of films before and post electrolysis indicated the same quantity of $\mathrm{Ni}$, suggesting that no part of the catalyst, homogeneous or heterogeneous, is lost from the films during catalysis (Supplementary Tables 1 and 4).

Characterization of $\mathrm{Ni}_{3}(\mathrm{HITP})_{2}$ before and after ORR. Spectroscopic, microscopic and diffractometric techniques enabled analysis of the film before and after ORR catalysis. X-ray photoelectron spectroscopy (XPS) of catalyst films before and after catalysis revealed an increase in binding energy of the $\mathrm{Ni}_{2 \mathrm{p}}$ envelope region $(850-885 \mathrm{eV}$ ) by $+1.0 \mathrm{eV}$ (Supplementary Fig. 7). Also visible by XPS was a shoulder peak that was present in the $\mathrm{N}_{1 \mathrm{~s}}$ region before ORR $(399 \mathrm{eV})$ which disappears after catalysis (Supplementary Fig. 8). Importantly, though the catalyst may undergo minor structural rearrangement during ORR, the high activity is largely retained over extended steady-state measurements, that is, neither access to the active sites nor the integrity of the active sites themselves is severely compromised during prolonged electrocatalysis. The structural robustness was supported by Raman spectroscopy conducted on the unused film, the film after submersion in the $0.10 \mathrm{M} \mathrm{KOH}$ electrolyte, and the film after electrochemical cycling under either $\mathrm{N}_{2}$ or $\mathrm{O}_{2}$. There were no missing or additional Raman bands for any of the altered films compared with the spectrum of the unused film (Supplementary Fig. 9). Additional evidence supporting the stability of the film was observed in scanning electron micrographs (SEMs) of the film taken before and after ORR catalysis (Supplementary Fig. 10). No perturbations in the morphology of the film were observed upon electrochemical cycling under $\mathrm{O}_{2}$. Finally, grazing incidence X-ray diffraction of

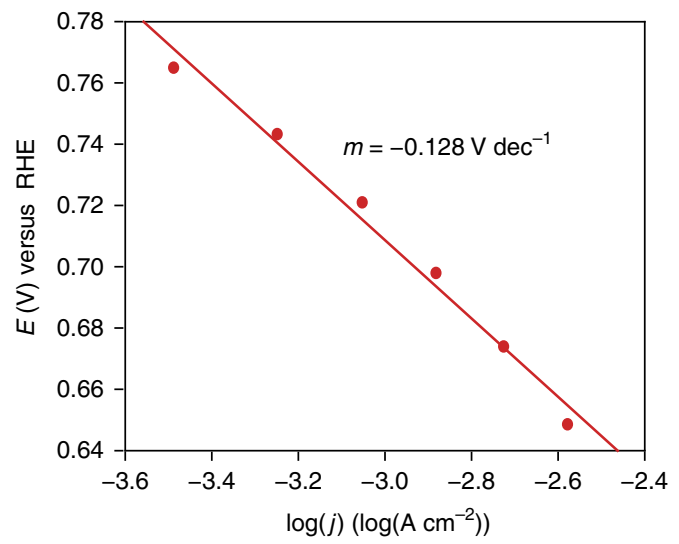

Figure 3 | ORR Tafel plot. Activation-controlled Tafel plot for $\mathrm{Ni}_{3}(\mathrm{HITP})_{2}{ }^{-}$ electrocatalyzed ORR, derived from the Koutecky-Levich plots (Supplementary Fig. 13).

the $\mathrm{Ni}_{3}(\mathrm{HITP})_{2}$ film before and after ORR catalysis showed retention of the long-range order in the $a b$ plane of $\mathrm{Ni}_{3}(\mathrm{HITP})_{2}$ during ORR, further highlighting the structural stability of this catalyst during electrochemical cycling under $\mathrm{O}_{2}$ (Supplementary Fig. 11).

ORR kinetics on $\mathrm{Ni}_{3}(\mathrm{HITP})_{2}$. Using standard rotating ring-disk electrode experiments (Supplementary Fig. 12) and assuming that catalytically competent sites within $\mathrm{Ni}_{3}(\mathrm{HITP})_{2}$ are distributed homogeneously throughout the film and not just on the surface, lower limit turnover frequencies (TOFs), determined by AAS, were found to be 0.042 electrons $\left[\mathrm{Ni}_{3}(\mathrm{HITP})_{2}\right]^{-1} \mathrm{~s}^{-1}$ and 0.052 electrons $\left[\mathrm{Ni}_{3}(\mathrm{HITP})_{2}\right]^{-1} \mathrm{~s}^{-1}$ for $\mathrm{H}_{2} \mathrm{O}_{2}$ and $\mathrm{H}_{2} \mathrm{O}$ production, respectively, at $E=0.79 \mathrm{~V}$. Quantifying the $\mathrm{Ni}$ content in the same films by ICP-MS gave lower limit TOF values of 0.046 electrons $\left[\mathrm{Ni}_{3}(\mathrm{HITP})_{2}\right]^{-1} \mathrm{~s}^{-1}$ and 0.056 electrons $\left[\mathrm{Ni}_{3}(\mathrm{HITP})_{2}\right]^{-1} \mathrm{~s}^{-1}$ for $\mathrm{H}_{2} \mathrm{O}_{2}$ and $\mathrm{H}_{2} \mathrm{O}$ production, respectively, also at $E=0.79 \mathrm{~V}$ (Supplementary Tables 1-6). The TOF values for $\mathrm{H}_{2} \mathrm{O}_{2}$ and $\mathrm{H}_{2} \mathrm{O}$ production increase by one order of magnitude to 0.491 electrons $\left[\mathrm{Ni}_{3}(\mathrm{HITP})_{2}\right]^{-1} \mathrm{~s}^{-1}$ and 0.466 electrons $\left[\mathrm{Ni}_{3}(\mathrm{HITP})_{2}\right]^{-1} \mathrm{~s}^{-1}$, respectively, at $0.67 \mathrm{~V}$. If the active sites in $\mathrm{Ni}_{3}(\mathrm{HITP})_{2}$ are the $\mathrm{Ni}$ atoms, the lower limit TOFs derived from AAS quantification of $\mathrm{Ni}$ are 0.014 electrons [Ni] $]^{-1} \mathrm{~s}^{-1}$ and 0.017 electrons $[\mathrm{Ni}]^{-1} \mathrm{~s}^{-1}$ for $\mathrm{H}_{2} \mathrm{O}_{2}$ and $\mathrm{H}_{2} \mathrm{O}$ production, respectively, at $E=0.79 \mathrm{~V}$. Minimum TOF values calculated from the ICP-MS quantification of $\mathrm{Ni}$ were 0.015 electrons $[\mathrm{Ni}]^{-1} \mathrm{~s}^{-1}$ and 0.019 electrons $[\mathrm{Ni}]^{-1} \mathrm{~s}^{-1}$ for $\mathrm{H}_{2} \mathrm{O}_{2}$ and $\mathrm{H}_{2} \mathrm{O}$ production, respectively, also at $E=0.79 \mathrm{~V}$. Notably, the intrinsic ORR turnover frequencies for $\mathrm{Ni}_{3}(\mathrm{HITP})_{2}$ could exceed the values reported here because the Ni quantification methods do not distinguish exclusively electroactive $\mathrm{Ni}$ sites; if some fraction of the potentially active sites are not catalytically competent because of mass transport limitations within the films, the ORR current-to-active-site ratio would increase, consequently increasing the TOF.

Mechanistic insight into $\mathrm{ORR}$ on $\mathrm{Ni}_{3}(\mathrm{HITP})_{2}$. The activationcontrolled Tafel plot generated from Koutecky-Levich (K-L) data (Supplementary Fig. 13) revealed a Tafel slope of $-128 \mathrm{mV} \mathrm{dec}{ }^{-1}$ (Fig. 3). This Tafel slope corresponds to an irreversible one-electron pre-equilibrium process, likely indicating the formation of the superoxide anion as the rate-limiting step (theoretical Tafel slope $=-120 \mathrm{mV} \mathrm{dec}^{-1}$ ). The total number of electrons transferred during ORR was determined using the inverse of the slope of the $\mathrm{K}-\mathrm{L}$ plots, termed the $B$ factor 
(equation (1)):

$$
B=0.62 n F D_{\mathrm{O}_{2}}^{2 / 3} v^{-1 / 6} c_{\mathrm{O}_{2}}\left(\frac{2 \pi}{60}\right)^{1 / 2}
$$

where $n=$ number of electrons transferred, $F=$ Faraday's constant, $D_{\mathrm{O}_{2}}=\mathrm{O}_{2}$ diffusion coefficient in the electrolyte, $v=$ kinematic viscosity of the electrolyte, and $c_{\mathrm{O}_{2}}=$ the saturation concentration of $\mathrm{O}_{2}$ in the electrolyte at $1 \mathrm{~atm} \mathrm{O}_{2}$ pressure. Assuming the typical values in $0.10 \mathrm{M} \mathrm{KOH}: D_{\mathrm{O}_{2}}=1.9 \times 10^{-5} \mathrm{~cm} \mathrm{~s}^{-1}, v=0.1 \mathrm{~m}^{2} \mathrm{~s}^{-1}$ (ref. 7), and $c_{\mathrm{O}_{2}}=1.26 \times 10^{-6} \mathrm{~mol} \mathrm{~cm}^{-3}$, and using $B=0.0831 \mathrm{~mA} \mathrm{~cm}^{-2}$ r.p.m. ${ }^{-1 / 2}$ from the $\mathrm{K}-\mathrm{L}$ plot at $E=0.767 \mathrm{~V}$, the number of transferred electrons in our system was calculated to be $n=2.25$ (Supplementary Table 7). This electron transfer number is consistent with predominant (87.5\%) production of $\mathrm{H}_{2} \mathrm{O}_{2}$ (more accurately, production of $\mathrm{HO}_{2}^{-}$in $0.10 \mathrm{M} \mathrm{KOH}$ given the $\mathrm{p} K_{\mathrm{a}}$ of $\left.\mathrm{H}_{2} \mathrm{O}_{2}=11.63\right)^{45}$, with the remaining activity ascribed to $4 \mathrm{e}^{-}$reduction to $\mathrm{H}_{2} \mathrm{O}$.

The Faradaic efficiency for $\mathrm{H}_{2} \mathrm{O}_{2}$ production was determined by measuring the ratio of the ring current to the disk current in rotating ring-disk electrochemical experiments (see Methods section). In the $0.82-0.54 \mathrm{~V}$ potential range, the Faradaic efficiency for $\mathrm{H}_{2} \mathrm{O}_{2}$ production decreases from 100 to $63 \%$ (Fig. 4) as formation of $\mathrm{H}_{2} \mathrm{O}$ increases with increasing overpotential before reaching a plateau at $\sim 0.75 \mathrm{~V}$.

The $\mathrm{H}^{+}$order for ORR catalysis was probed galvanostatically at $I=-5.0 \mu \mathrm{A}$ in a $0.1 \mathrm{M} \mathrm{NaClO}_{4} / 0.1 \mathrm{M} \mathrm{NaOH}$ aqueous electrolyte titrated from $\mathrm{pH} 12.89$ to 11.54 with $1.0 \mathrm{M} \mathrm{HClO}_{4}$. These studies revealed a slope of zero for $\delta E / \delta \mathrm{pH}$ above $\mathrm{pH} 12.80$, suggesting a zeroth order dependence on $\left[\mathrm{H}^{+}\right]$for the kinetic rate law (Supplementary Fig. 14). However, a non-zero slope was observed below $\mathrm{pH} 12.80$, indicating a change in mechanism that involves proton-coupled electron transfer or proton-dependent chemical steps before or during the rate-limiting step (Supplementary Note 1). Detailed mechanistic investigations of ORR with our catalyst are currently underway.

\section{Discussion}

Direct adhesion of the $\mathrm{Ni}_{3}(\mathrm{HITP})_{2}$ film onto the electrode surface eliminates the need for binders or conductive additives that may block access to active sites by pore filling. This direct contact between the parent material and the electrode allowed for investigation of the inherent electrocatalytic behaviour of pure $\mathrm{Ni}_{3}(\mathrm{HITP})_{2}$. The high surface area and porosity inherent to $\mathrm{Ni}_{3}(\mathrm{HITP})_{2}$ may increase the density of and facilitate easy access to the catalytic active sites on $\mathrm{Ni}_{3}(\mathrm{HITP})_{2}$, contributing to the notable ORR activity. Given that this high ORR activity is observed after the film purification procedure which involves



Figure 4 | Faradaic efficiency for $\mathbf{H}_{\mathbf{2}} \mathbf{O}_{\mathbf{2}}$ and $\mathbf{~}_{\mathbf{H}} \mathbf{H}_{\mathbf{2}} \mathbf{O}_{\mathbf{2}}$. Potential-dependent Faradaic efficiency for $\mathrm{H}_{2} \mathrm{O}_{2}$ production and $\% \mathrm{H}_{2} \mathrm{O}_{2}$ production during ORR catalysed by $\mathrm{Ni}_{3}(\mathrm{HITP})_{2}$ at $\mathrm{pH} 13$. heating the modified electrode in methanol at $65^{\circ} \mathrm{C}$ for $20 \mathrm{~h}$, $\mathrm{Ni}_{3}(\mathrm{HITP})_{2}$ and related materials may be strong candidates for implementation into direct methanol fuel cells where methanol tolerance of the anodic and cathodic catalysts is a necessity ${ }^{46}$. High stability in the presence of methanol is not observed for Pt-based electrocatalysts, a major hurdle currently slowing direct methanol fuel cell development ${ }^{47}$.

Further insight into the robustness of $\mathrm{Ni}_{3}(\mathrm{HITP})_{2}$ during ORR was achieved using several spectroscopic and microscopic techniques to probe the catalyst structure before and after catalysis. The $+1 \mathrm{eV}$ shift in the $\mathrm{Ni}_{2 p}$ XPS after ORR catalysis could be indicative of a Ni-O interaction ${ }^{48,49}$, or alternatively a strengthening of the ligand field as electron density around the imine decreases. The loss of asymmetry in the $\mathrm{N}_{1 \mathrm{~s}}$ region of the XPS after catalysis is consistent with an alteration of the ligand field during ORR. Though some minor changes in the film structure may take place during ORR, retention of the majority of ORR activity over the steady-state potentiostatic measurements provides encouraging evidence that neither access to the active sites nor the integrity of the active sites themselves is severely compromised during prolonged electrocatalysis. Furthermore, any subtle alterations of the film affected neither the film's microstructure nor the polarizability of the $\mathrm{Ni}_{3}(\mathrm{HITP})_{2}$ bonds as shown by SEM and Raman spectroscopy, respectively. The stability of the catalyst in aqueous media is industrially advantageous given the lower cost of water-based electrolytes.

To the best of our knowledge, the foregoing results demonstrate for the first time electrocatalytic ORR activity in a well-defined, intrinsically conductive MOF. Clearly, the faradaic efficiency for water production should be increased for maximizing energy density in industrial settings, but such a goal may be more tractable with MOFs, whose well-defined structures provide the ability to systematically investigate a number of variables including the metal centre identity, valency and coordination environment. Structure-function and mechanistic studies will facilitate understanding, development, and diversification of this material into a platform structure primed for the targeted design of other ORR electrocatalysts.

\section{Methods}

Characterization of the $\mathbf{N i}_{\mathbf{3}}(\mathbf{H I T P})_{\mathbf{2}}$ film. Samples were prepared for ICP-MS and AAS analysis by sonication of the modified electrode buttons in concentrated ICP (Omnitrace purity, 67-70\% w/w; EMD) grade nitric acid for $4 \mathrm{~h}$. The electrode buttons were removed from the acid, and the acid was diluted to $2 \% \mathrm{v} / \mathrm{v}$ with Milli-Q water. ICP-MS was conducted on an Agilent 7900 at the MIT Center for Environmental and Health Sciences (Cambridge, MA, USA). An external calibration curve was generated with a nickel standard (1,000 p.p.m. in $2 \% \mathrm{HNO}_{3}$; Ultra Scientific) diluted to 0, 15, 30, 60 and 120 p.p.b. in $2 \%$ ICP grade nitric acid. Argon flowing at $1.06 \mathrm{~min}^{-1}$ was used as the carrier gas. The ICP-MS data was analysed by MassHunter 4.1 software.

Graphite furnace AAS was conducted on a Perkin Elmer AAnalyst 600 GFAAS (property of the Lippard Group, MIT, Cambridge, MA, USA). An ICP grade Ni standard ( 1,000 p.p.m. in $2 \% \mathrm{HNO}_{3}$ ) (Ultra Scientific) was diluted to 100 p.p.b. in $2 \%$ $\mathrm{HNO}_{3}$ in Milli-Q water. The AAS performed a serial dilution to generate a nickel calibration curve with $0,25,50,75$ and 100 p.p.b. nickel calibration points. The nickel content was probed by monitoring the optical absorption at $\lambda=232.0 \mathrm{~nm}$. The graphite furnace temperature was ramped from 110 to $2,500^{\circ} \mathrm{C}$ during AAS analysis. The AAS results were analysed by WinLab32 for AA, version 6.5.0.0266.

Atomic force microscopy was conducted at the MIT Institute for Soldier Nanotechnologies (Cambridge, MA, USA) using a Veeco Dimension 3,100 scanning probe microscope (Veeco Digital Instruments by Bruker) equipped with a Nanoscope $\mathrm{V}$ controller. Images were recorded in tapping mode in the air at room temperature $\left(23-25^{\circ} \mathrm{C}\right)$ using an $\mathrm{Al}$ reflex coated silicon micro cantilever (AC240TS-R3, Asylum Research). The scan rate was set at $1.0 \mathrm{~Hz}$. The atomic force microscopy results were analysed by Gwyddion 2.43 software.

XPS was conducted at the Harvard Center for Nanoscale Systems (Cambridge, MA, USA) on a Thermo Scientific K-Alpha XPS. A survey scan was taken and C, $\mathrm{N}, \mathrm{O}$ and $\mathrm{Ni}$ were probed with a pass energy $=50 \mathrm{eV}$, beam width $=400 \mu \mathrm{m}$. Data analysis was executed with the Advantage 5.938 software programme.

Raman spectroscopy was conducted on a Horiba Raman spectrophotometer (property of the Myerson Group, MIT, Cambridge, MA, USA) operated at $457 \mathrm{~nm}$ 
with a hole diameter of $500 \mu \mathrm{m}$, a slit size of $100 \mu \mathrm{m}$, a range of $100-3,000 \mathrm{~cm}^{-1}$, a $100 \times$ magnification lens, a laser intensity of $39 \mathrm{~A}$, and $2 \mathrm{~s}$ runs with three accumulations per sample.

Scanning electron microscopy was conducted at the Harvard Center for Nanoscale Systems (Cambridge, MA, USA) on a Zeiss Ultra Plus FE-SEM with an InLens detector, a voltage of $10 \mathrm{kV}$, and $200 \mathrm{k} \times$ magnification. Data analysis was executed with SmartSEM V05.04.02.00 software.

Grazing incidence X-ray diffraction was conducted at the MIT Center for Materials Science and Engineering (Cambridge, MA, USA) on a Bruker D8 Discover Diffractometer with a Vantec 2,000 two-dimensional detector, a $\mathrm{Cu} \mathrm{K}_{\alpha} \mathrm{X}$-ray source $(1.5409 \AA)$, and a tube voltage and current of $40 \mathrm{kV}$ and $40 \mathrm{~mA}$, respectively. The diffraction patterns were collected in a grazing incidence geometry with a grazing incidence angle of $3.6^{\circ}$. The blank indium tin oxide slide and the indium tin oxide slides modified with the $\mathrm{Ni}_{3}(\mathrm{HITP})_{2}$ film were secured onto the diffractometer stage with double-sided tape during data collection. The data for each sample was collected in a single exposure with an exposure time of $10 \mathrm{~min}$ per sample. The two-dimensional data were reduced by azimuth averaging over $180^{\circ}$ of the Debye Scherrer ring. It is noted that the remaining $180^{\circ}$ of the Debye Scherrer ring was blocked by the sample due to the grazing incidence geometry.

Electrochemistry with the $\mathbf{N i}_{\mathbf{3}}(\mathbf{H I T P})_{\mathbf{2}}$ film. $\mathrm{KOH}(99.99 \%$ trace metals) was purchased from Sigma-Aldrich. Oxygen gas was purchased from Airgas (99.8\% purity). Reference and glassy carbon working electrodes were purchased from $\mathrm{CH}$ Instruments. Pt gauze (100 mesh, 99.9\% metal basis) and wires $(\phi=0.404 \mathrm{~mm}$, annealed, $99.9 \%$ metal basis, and $\phi=0.5 \mathrm{~mm}$ dia., hard, $99.95 \%$ metal basis) comprising the auxiliary electrode were purchased from Alfa Aesar. The auxiliary electrode was cleaned by submersion in concentrated $\mathrm{HCl}$ followed by sonication for $5 \mathrm{~min}$, washing with Milli-Q water, and drying under a stream of air before each experiment. Working electrodes were cleaned by submersion in concentrated $\mathrm{HCl}$ followed by sonication for $5 \mathrm{~min}$, washing with Milli-Q water, and drying under a stream of air. The working electrodes were then sequentially polished with 100, 30 and $5 \mu \mathrm{m}$ diameter alumina powder from BASI. Unless otherwise noted, all electrochemical experiments were executed with a Bio-Logic SP200 potentiostat/galvanostat in a custom 2-compartment electrochemical cell. Rotating disk electrode and rotating ring-disk electrode studies were conducted with a Bio-Logic VMP3 potentiostat/galvanostat Pine Research Instrumentation Modulated Speed Rotator. Unless otherwise specified, internal resistance of the electrolyte was measured with the Bio-Logic SP200 potentiostat/galvanostat, and iR drop correction was applied. Generally, the resistance of $0.10 \mathrm{M} \mathrm{KOH}$ was measured to be $\sim 40 \Omega$.

\section{Synthesis of the $\mathbf{N i}_{3}$ (HITP) $)_{2}$ film on glassy carbon electrode. $2,3,6,7,10,11$ -} hexaaminotriphenylene hexahydrochloric acid (HATP $\cdot 6 \mathrm{HCl})$ salt $(10.4 \mathrm{mg})$ was dissolved in Milli-Q water $(6 \mathrm{ml})$ and heated to $65^{\circ} \mathrm{C}$ with stirring in a $20 \mathrm{ml}$ capped glass vial (Vial A). In a second glass reaction vial (Vial B), nickel(II) chloride hexahydrate $(4.6 \mathrm{mg})$ was dissolved in Milli-Q water $(4 \mathrm{ml})$ and to this was added concentrated aqueous ammonium hydroxide $(0.4 \mathrm{ml}, 25 \%$ aqueous solution). The heated HATP solution in Vial A was added to the $\mathrm{NiCl}_{2} / \mathrm{NH}_{4} \mathrm{OH}$ solution (Vial B) and two alumina micropolished glassy carbon electrodes ( $5 \mathrm{~mm}$ diameter) were placed in the reaction so that the polished faces of the glassy carbon buttons were parallel to the bottom of the reaction vial. Each button was inserted into an NMR tube cap so that only the polished face of the glassy carbon was exposed for modification. The vial was capped and the reaction was heated without stirring at $65^{\circ} \mathrm{C}$ for $15 \mathrm{~h}$. The next day, the reaction afforded a translucent film on the glassy carbon electrode buttons. Additionally, a translucent black film was visible on the reaction vial walls and a black flaky solid had settled at the bottom of the reaction vial. The electrode film and the reaction mixture solid were purified separately.

The electrode was removed from the reaction mixture and heated in Milli-Q water $(20 \mathrm{ml})$ at $65^{\circ} \mathrm{C}$ for $4 \mathrm{~h}$ in a capped vial, rinsed with Milli-Q water, then heated again in water at $65^{\circ} \mathrm{C}$ for $15 \mathrm{~h}$ in a capped vial. The electrode was rinsed with $\mathrm{CH}_{3} \mathrm{OH}$ and then heated in fresh $\mathrm{CH}_{3} \mathrm{OH}$ in a capped vial at $65^{\circ} \mathrm{C}$ for $5 \mathrm{~h}$. The $\mathrm{CH}_{3} \mathrm{OH}$ was removed and the electrode was heated at $65^{\circ} \mathrm{C}$ for $15 \mathrm{~h}$ in fresh $\mathrm{CH}_{3} \mathrm{OH}$. The next day after drying under dynamic vacuum, a black translucent film coating the polished side of the glassy carbon button was visible. The electrode button was stored under dynamic vacuum.

For purification of the black powder, the remaining reaction mixture was centrifuged, the supernatant was removed, and the remaining solid was sonicated in Milli-Q water $(15 \mathrm{ml})$ for $5 \mathrm{~min}$ then heated in a capped vial with stirring at $65^{\circ} \mathrm{C}$ for $4 \mathrm{~h}$. The same procedure was repeated once more, with the final heating step duration of $15 \mathrm{~h}$. The powder was once again centrifuged, followed by removal of the supernatant, and then the powder was sonicated in $\mathrm{CH}_{3} \mathrm{OH}(15 \mathrm{ml})$ for $5 \mathrm{~min}$, then heated in the capped vial in $\mathrm{CH}_{3} \mathrm{OH}$ at $65^{\circ} \mathrm{C}$ for $5 \mathrm{~h}$. The $\mathrm{CH}_{3} \mathrm{OH}$ wash procedure was also repeated one more time, then the powder was centrifuged, the supernatant was removed, and the black solid was dried under vacuum for $15 \mathrm{~h}$.

Determination of the 2-and-4-electron ORR TOFs. The background-subtracted ring current (Supplementary Fig. 12) was taken for each potential probed during potentiostatic measurements $\left(E_{\text {disk }}=0.807,0.787,0.767,0.747,0.727,0.707,0.687\right.$, and $0.667 \mathrm{~V}$ ) then divided by 1,000 to calculate current passed in $\mathrm{A}=\mathrm{C} \mathrm{s}^{-1}$ $(I=Q / t)$. That current was divided by 0.2 to account for the $20 \%$ ring collection efficiency, then divided by Faraday's constant $\left(96,485.3365 \mathrm{C} \mathrm{mol}^{-1}\right)$ and multiplied by Avogadro's number $\left(6.022 \times 10^{23}\right.$ electrons per mol) to determine the number of electrons transferred to $\mathrm{O}_{2}$ when reducing $\mathrm{O}_{2}$ to $\mathrm{H}_{2} \mathrm{O}_{2}$ (2-electron ORR) per second. By ICP-MS the electrode was calculated to have an average of $1.1015 \times 10^{16}$ nickel sites deposited (see Supplementary Table 1 for s.d.). By AAS, the electrode was calculated to have an average of $1.26199 \times 10^{16}$ nickel sites deposited (see Supplementary Table 4 for s.d.). The number of electrons transferred per second was divided by the number of nickel sites as determined by AAS and ICP-MS, respectively, to convert the 2-electron ORR TOF to electrons nickel per site per second according to the two nickel quantification methods (that is, AAS and ICP-MS) (Supplementary Tables 2 and 5). Alternatively, the number of electrons transferred per second was divided by the number of $\mathrm{Ni}_{3}(\mathrm{HITP})_{2}$ units to convert the 2-electron ORR TOF to electrons per $\mathrm{Ni}_{3}(\mathrm{HITP})_{2}$ formula unit per second. The number of $\mathrm{Ni}_{3}(\mathrm{HITP})_{2}$ formula units was directly calculated from the number of nickel sites derived from the two nickel quantification methods. In the main text, the TOF is expressed as a range defined by the values calculated using the two employed nickel quantification methods.

To determine the TOF for 4-electron ORR, the background and collection efficiency-corrected ring current was subtracted from the disk current (A) (Supplementary Fig. 12) to obtain the current passed during 4-electron ORR. The current (A) was divided by Faraday's constant then by number of nickel or $\mathrm{Ni}_{3}(\mathrm{HITP})_{2}$ sites to calculate the TOF (electrons per nickel site per second, or electrons per $\mathrm{Ni}_{3}(\mathrm{HITP})_{2}$ formula unit per second, respectively) during 4-electron ORR according to the two employed nickel quantification methods (Supplementary Tables 3 and 6). In the main text, the TOF is expressed as a range defined by the values calculated using the two employed nickel quantification methods.

Rotating disk and rotating ring-disk electrode investigations. Experiments were conducted in a two-compartment cell with a glass frit separating the auxiliary electrode from the working electrode; electrolyte $=0.10 \mathrm{M} \mathrm{KOH}$; auxiliary electrode $=\mathrm{Pt}$ mesh; reference electrode $=\mathrm{Hg} / \mathrm{HgO}(1.00 \mathrm{M} \mathrm{KOH})$, working electrode $=$ blank glassy carbon button ( $5 \mathrm{~mm}$ diameter) or glassy carbon button modified with $\mathrm{Ni}_{3}(\mathrm{HITP})_{2}$ film and inserted in a polyarylether-ether ketone rotating ring-disk electrode $(\mathrm{RRDE})$ tip with a platinum ring; rotation rate $=2,000$ r.p.m.; scan speed $=5 \mathrm{mV} \mathrm{s}^{-1}$; atmosphere $=\mathrm{N}_{2}$ or $\mathrm{O}_{2}$ sparged for $10 \mathrm{~min}$ through a fritted sparge tube before data collection, with continuous sparging during data collection. All voltammograms were collected by scanning cathodically from $E=0 \mathrm{~V}$ versus open circuit potential (OCP) to $-0.300 \mathrm{~V}$ versus $\mathrm{Hg} / \mathrm{HgO}(0.567 \mathrm{~V}$ versus $\mathrm{RHE})$. The electrolyte solvent window was established by cycling a blank glassy carbon button under $\mathrm{N}_{2}$ atmosphere. ORR activity of the unmodified glassy carbon was observed by cycling the unmodified glassy carbon electrode under $\mathrm{O}_{2}$ from $E=0 \mathrm{~V}$ versus OCP to $E=0.400 \mathrm{~V}$ versus RHE. These controls preceded data collection of $\mathrm{Ni}_{3}(\mathrm{HITP})_{2}-$ modified glassy carbon under $\mathrm{N}_{2}$ and $\mathrm{O}_{2}$ atm. When relevant, a potential of $E=1.23 \mathrm{~V}$ versus RHE was applied to the Pt ring disk for oxidation of the ORR products. A $20 \%$ collection efficiency was applied for quantification of the ORR products using the current measured at the Pt ring disk.

Potentiostatic steady-state durability test. While rotating at 2,000 r.p.m., cyclic voltammetry $(\mathrm{CV})$ of the $\mathrm{Ni}_{3}(\mathrm{HITP})_{2}$-modified glassy carbon electrode was conducted at $5 \mathrm{mV} \mathrm{s}^{-1}$ from $E=0 \mathrm{~V}$ versus OCP to $E=-0.3 \mathrm{~V}$ versus $\mathrm{Hg} / \mathrm{HgO}$ ( $E=0.567 \mathrm{~V}$ versus $\mathrm{RHE})$ under sparging $\mathrm{O}_{2}$ atmosphere to measure the ORR activity. In this experiment, a titanium plate auxiliary electrode was used. $\mathrm{O}_{2}$ sparged throughout the entirety of the experiment. The potential was held at $E=0.767 \mathrm{~V}$ versus $\mathrm{RHE}$ for $8 \mathrm{~h}$ with $\mathrm{O}_{2}$ sparging continuously. The current response was monitored with data points collected every $60 \mathrm{~s}$. After the potentiostatic stability test was completed, $\mathrm{CV}$ was conducted again under $\mathrm{O}_{2}$ atmosphere at $5 \mathrm{mV} \mathrm{s}^{-1}$ from $E=0 \mathrm{~V}$ versus OCP to $E=-0.3 \mathrm{~V}$ versus $\mathrm{Hg} / \mathrm{HgO}$ to compare the mass transport of the used material to that of the material before the stability test.

Koutecky-Levich and Tafel studies. $\mathrm{CV}\left(5 \mathrm{mV} \mathrm{s}^{-1}\right)$ under $\mathrm{N}_{2}$ atmosphere was conducted from $0 \mathrm{~V}$ versus OCP to $-0.3 \mathrm{~V}$ versus $\mathrm{Hg} / \mathrm{HgO}$ (ORR potential range for $\left.\mathrm{Ni}_{3}(\mathrm{HITP})_{2}\right)$. CV $\left(5 \mathrm{mV} \mathrm{s}^{-1}\right)$ under $\mathrm{O}_{2}$ atmosphere was conducted from $0 \mathrm{~V}$ versus OCP to $-0.3 \mathrm{~V}$ versus $\mathrm{Hg} / \mathrm{HgO}$ (ORR potential range for $\mathrm{Ni}_{3}(\mathrm{HITP})_{2}$ ). Galvanostatic measurements were conducted with $I=-1,-10$ and $-100 \mu \mathrm{A}$ to identify the reliable potential range for potentiostatic measurements. Potentiostatic measurements were conducted from -20 to $-200 \mathrm{mV}$ versus $\mathrm{Hg} / \mathrm{HgO}$ in increments of $20 \mathrm{mV}$. Each potential was held for $1 \mathrm{~min}$. This was conducted five times, with altering rotation speeds to extrapolate the diffusion coefficient. The electrode was rotated at 2,000,625,816, 550 and 1,189 r.p.m., respectively. This allowed for elimination of mass transport limitations when analysing Tafel behaviour via generation of the activation-controlled Tafel plot. $\mathrm{CV}\left(5 \mathrm{mV} \mathrm{s}^{-1}\right)$ under $\mathrm{O}_{2}$ atmosphere was conducted from $0 \mathrm{~V}$ versus OCP to $-0.3 \mathrm{~V}$ versus $\mathrm{Hg} / \mathrm{HgO}(\mathrm{ORR}$ potential range for $\left.\mathrm{Ni}_{3}(\mathrm{HITP})_{2}\right)$. Chronoamperometry at $E=-0.2 \mathrm{~V}$ versus $\mathrm{Hg} / \mathrm{HgO}$ was run for 8 min under $\mathrm{N}_{2}$ sparging atmosphere to eliminate $\mathrm{O}_{2}$. CV $\left(5 \mathrm{mV} \mathrm{s}^{-1}\right)$ under $\mathrm{N}_{2}$ atmosphere was conducted from $0 \mathrm{~V}$ versus OCP to $-0.3 \mathrm{~V}$ versus $\mathrm{Hg} / \mathrm{HgO}$ (ORR potential range for $\mathrm{Ni}_{3}(\mathrm{HITP})_{2}$ ) to recheck the double layer capacitance as an indicator of potential catalyst decomposition. Ohmic drop was measured at $I=-0.1 \mathrm{~mA}$ for iR correction. 
ORR proton order study. Potential was measured over $25 \mathrm{~min}$ at a constant current $I=-5 \mu \mathrm{A}$ while varying the $\mathrm{pH}$ from 12.89 to 11.54 in the $0.10 \mathrm{M} \mathrm{KOH}$ electrolyte titrated with $1.0 \mathrm{M} \mathrm{HClO}_{4}$.

\section{References}

1. Jasinski, R. Cobalt phthalocyanine as a fuel cell cathode. J. Electrochem. Soc. 112, 526-528 (1965).

2. Tang, H. et al. Molecular architecture of cobalt porphyrin multilayers on reduced graphene oxide sheets for high-performance oxygen reduction reaction. Angew. Chem. Int. Ed. 52, 5585-5589 (2013).

3. Schafer, F. P. et al. Physical and Chemical Applications of Dyestuffs (Springer, 1976).

4. Masa, J., Xia, W., Muhler, M. \& Schuhmann, W. On the role of metals in nitrogen-doped carbon electrocatalysts for oxygen reduction. Angew. Chem. Int. Ed. 54, 10102-10120 (2015).

5. Chen, Z., Higgins, D., Yu, A., Zhang, L. \& Zhang, J. A review on non-precious metal electrocatalysts for PEM fuel cells. Energy Environ. Sci. 4, 3167-3192 (2011).

6. Mao, J., Yang, L., Yu, P., Wei, X. \& Mao, L. Electrocatalytic four-electron reduction of oxygen with copper(II)-based metal-organic frameworks. Electrochem. Commun. 19, 29-31 (2012).

7. Jahan, M., Bao, Q. \& Loh, K. P. Electrocatalytically active graphene-porphyrin MOF composite for oxygen reduction reaction. J. Am. Chem. Soc. 134, 6707-6713 (2012).

8. Jahan, M., Liu, Z. \& Loh, K. P. A graphene oxide and copper-centered metal organic framework composite as a tri-functional catalyst for HER, OER, and ORR. Adv. Funct. Mater. 23, 5363-5372 (2013).

9. Jiang, M., Li, L., Zhu, D., Zhang, H. \& Zhao, X. Oxygen reduction in the nanocage of metal-organic frameworks with an electron transfer mediator. J. Mater. Chem. A 2, 5323-5329 (2014).

10. Wang, H., Yin, F., Chen, B. \& Li, G. Synthesis of an $\varepsilon-\mathrm{MnO}_{2} /$ metal-organicframework composite and its electrocatalysis towards oxygen reduction reaction in an alkaline electrolyte. J. Mater. Chem. A 3, 16168-16176 (2015).

11. Barkholtz, H., Chong, L., Kaiser, Z., Xu, T. \& Liu, D.-J. Highly active non-PGM catalysts prepared from metal organic frameworks. Catalysts 5, 955-965 (2015).

12. Clough, A. J., Yoo, J. W., Mecklenburg, M. H. \& Marinescu, S. C. Twodimensional metal-organic surfaces for efficient hydrogen evolution from water. J. Am. Chem. Soc. 137, 118-121 (2015).

13. Hinogami, R. et al. Electrochemical reduction of carbon dioxide using a copper rubeanate metal organic framework. ECS Electrochem. Lett. 1, H17-H19 (2012).

14. Lin, S. et al. Covalent organic frameworks comprising cobalt porphyrins for catalytic $\mathrm{CO}_{2}$ reduction in water. Science 349, 1208-1213 (2015).

15. Dong, R. et al. Large-area, free-standing, two-dimensional supramolecular polymer single-layer sheet for highly efficient electrocatalytic hydrogen evolution. Angew. Chem. Int. Ed. 54, 12058-12063 (2015).

16. Zhang, P., Hou, X., Liu, L., Mi, J. \& Dong, M. Two-dimensional $\pi$-conjugated metal bis(dithiolene) complex nanosheets as selective catalysts for oxygen reduction reaction. J. Phys. Chem. C 119, 28028-28037 (2015).

17. Sheberla, D. et al. High electrical conductivity in $\mathrm{Ni}_{3}(2,3,6,7,10,11$ hexaiminotriphenylene) $)_{2}$, a semiconducting metal-organic graphene analogue. J. Am. Chem. Soc. 136, 8859-8862 (2014).

18. Afsahi, F. \& Kaliaguine, S. Non-precious electrocatalysts synthesized from metal-organic frameworks. J. Mater. Chem. A 2, 12270-12279 (2014).

19. Aijaz, A., Fujiwara, N. \& Xu, Q. From metal-organic framework to nitrogendecorated nanoporous carbons: high $\mathrm{CO}_{2}$ uptake and efficient catalytic oxygen reduction. J. Am. Chem. Soc. 136, 6790-6793 (2014).

20. Li, J. et al. Metal-organic framework templated nitrogen and sulfur co-doped porous carbons as highly efficient metal-free electrocatalysts for oxygen reduction reactions. J. Mater. Chem. A 2, 6316-6319 (2014).

21. Li, Q. et al. Graphene/graphene-tube nanocomposites templated from cagecontaining metal-organic frameworks for oxygen reduction in $\mathrm{Li}-\mathrm{O}_{2}$ batteries. Adv. Mater. 26, 1378-1386 (2014)

22. Li, Q. et al. Metal-organic framework-derived bamboo-like nitrogen-doped graphene tubes as an active matrix for hybrid oxygen-reduction electrocatalysts. Small 11, 1443-1452 (2014)

23. Kong, A. et al. From cage-in-cage MOF to N-doped and Co-nanoparticleembedded carbon for oxygen reduction reaction. Dalton Trans. 44, 6748-6754 (2015).

24. Ge, L. et al. High activity electrocatalysts from metal-organic frameworkcarbon nanotube templates for the oxygen reduction reaction. Carbon 82, 417-424 (2015).

25. Palaniselvam, T., Biswal, B. P., Banerjee, R. \& Kurungot, S. Zeolitic imidazolate framework (ZIF)-derived, hollow-core, nitrogen-doped carbon nanostructures for oxygen-reduction reactions in PEFCs. Chemistry 19, 9335-9342 (2013).

26. Pandiaraj, S., Aiyappa, H. B., Banerjee, R. \& Kurungot, S. Post modification of MOF derived carbon via $\mathrm{g}-\mathrm{C}_{3} \mathrm{~N}_{4}$ entrapment for an efficient metal-free oxygen reduction reaction. Chem. Commun. 50, 3363-3366 (2014).
27. Strickland, K. et al. Highly active oxygen reduction non-platinum group metal electrocatalyst without direct metal-nitrogen coordination. Nat. Commun. 6, 7343-7351 (2015).

28. Kung, C.-W. et al. Metal-organic framework thin films composed of freestanding acicular nanorods exhibiting reversible electrochromism. Chem. Mater. 25, 5012-5017 (2013)

29. Xia, W. et al. Well-defined carbon polyhedrons prepared from nano metal-organic frameworks for oxygen reduction. J. Mater. Chem. A 2, 11606-11613 (2014).

30. Wang, X. et al. MOF derived catalysts for electrochemical oxygen reduction. J. Mater. Chem. A 2, 14064-14070 (2014).

31. Zhang, G. et al. One-step conversion from metal-organic frameworks to $\mathrm{Co}_{3} \mathrm{O}_{4} @ \mathrm{~N}$-doped carbon nanocomposites towards highly efficient oxygen reduction catalysts. J. Mater. Chem. A 2, 8184-8189 (2014).

32. Zhang, L. et al. Highly graphitized nitrogen-doped porous carbon nanopolyhedra derived from ZIF-8 nanocrystals as efficient electrocatalysts for oxygen reduction reactions. Nanoscale 6, 6590-6602 (2014).

33. Zhao, D. et al. Iron imidazolate framework as precursor for electrocatalysts in polymer electrolyte membrane fuel cells. Chem. Sci. 3, 3200-3205 (2012).

34. Zhao, D. et al. Highly efficient non-precious metal electrocatalysts prepared from one-pot synthesized zeolitic imidazolate frameworks. Adv. Mater. 26, 1093-1097 (2014).

35. Zhao, S. et al. Carbonized nanoscale metal-organic frameworks as high performance electrocatalyst for oxygen reduction reaction. ACS Nano $\mathbf{8}$, 12660-12668 (2014).

36. Zhao, X. et al. One-step synthesis of nitrogen-doped microporous carbon materials as metal-free electrocatalysts for oxygen reduction reaction. J. Mater. Chem. A 2, 11666-11671 (2014).

37. Zhu, D. et al. Nitrogen-doped porous carbons from bipyridine-based metalorganic frameworks: electrocatalysis for oxygen reduction reaction and Ptcatalyst support for methanol electrooxidation. Carbon 79, 544-553 (2014).

38. Gileadi, E. Physical Electrochemistry (Wiley-VCH Verlag GmbH \& Co, 2011).

39. Shi, H. et al. Recent advances of doped carbon as non-precious catalysts for oxygen reduction reaction. J. Mater. Chem. A 2, 15704-15716 (2014).

40. Serov, A. et al. Nano-structured non-platinum catalysts for automotive fuel cell application. Nano Energy 16, 293-300 (2015).

41. Xie, Y. et al. Carbonization of self-assembled nanoporous hemin with a significantly enhanced activity for the oxygen reduction reaction. Faraday Discuss. 176, 393-408 (2014).

42. Lin, Q. et al. Heterometal-embedded organic conjugate frameworks from alternating monomeric iron and cobalt metalloporphyrins and their application in design of porous carbon catalysts. Adv. Mater. 27, 3431-3436 (2015).

43. Wang, Y., Kong, A., Chen, X., Lin, Q. \& Feng, P. Efficient oxygen electroreduction: hierarchical porous $\mathrm{Fe}-\mathrm{N}$-doped hollow carbon nanoshells. ACS Catal. 5, 3887-3893 (2015).

44. Liu, Y. et al. Iron(II) phthalocyanine covalently functionalized graphene as a highly efficient non-precious-metal catalyst for the oxygen reduction reaction in alkaline media. Electrochim. Acta 112, 269-278 (2013).

45. Blizanac, B. B., Ross, P. N. \& Markovic, N. M. Oxygen electroreduction on $\mathrm{Ag}(111)$ : the pH effect. Electrochim. Acta 52, 2264-2271 (2007).

46. Zhao, S. et al. Three dimensional N-doped graphene/PtRu nanoparticle hybrids as high performance anode for direct methanol fuel cells. J. Mater. Chem. A 2 , 3719-3724 (2014)

47. Alonso-Vante, N. Platinum and non-platinum nanomaterials for the molecular oxygen reduction reaction. Chemphyschem. 11, 2732-2744 (2010).

48. Grosvenor, A. P., Biesinger, M. C., Smart, R. S. C. \& McIntyre, N. S. New interpretations of XPS spectra of nickel metal and oxides. Surf. Sci. 600, 1771-1779 (2006).

49. Biesinger, M. C., Payne, B. P., Lau, L. W. M., Gerson, A. \& Smart, R. S. C. X-ray photoelectron spectroscopic chemical state quantification of mixed nickel metal, oxide and hydroxide systems. Surf. Interface Anal. 41, 324-332 (2009)

\section{Acknowledgements}

This work was supported by the US Department of Energy, Office of Science, Office of Basic Energy Sciences (Award DESC0006937). We thank Dr M. Li for valuable discussions and assistance with XPS, Dr I. Riddell (Lippard Group, MIT) for assistance with AAS, Dr K. Taghizadeh (MIT Center for Environmental and Health Sciences) for assistance with ICP-MS, Dr S. Perala (Myerson Group, MIT) for assistance with Raman spectroscopy, Mr D. Lange (Harvard Center for Nanoscale Systems) for assistance with SEM, and Dr C. Settens (MIT Center for Materials Science and Engineering) for assistance with the grazing incidence X-ray diffraction.

\section{Author contributions}

T.F. assisted with the RRDE experimental setup and design of electrochemical proce dures. Y.S. provided electrochemical equipment. D.S. conducted $\mathrm{N}_{2}$ isotherms and Brunauer-Emmett-Teller surface area analysis of $\mathrm{Ni}_{3}(\mathrm{HITP})_{2}$. L.S. conducted atomic force microscopy measurements. E.M.M. prepared all samples for electrochemical 
investigations and all other analyses, and conducted the reported experiments. E.M.M., T.F., Y.S. and M.D. contributed to data analysis. E.M.M. and M.D. wrote the manuscript.

\section{Additional information}

Supplementary Information accompanies this paper at http://www.nature.com/ naturecommunications

Competing financial interests: The authors declare no competing financial interests.

Reprints and permission information is available online at http://npg.nature.com/ reprintsandpermissions/
How to cite this article: Miner, E. M. et al. Electrochemical oxygen reduction catalysed by $\mathrm{Ni}_{3}$ (hexaiminotriphenylene) ${ }_{2}$. Nat. Commun. 7:10942 doi: 10.1038/ncomms10942 (2016).

(c) (i) This work is licensed under a Creative Commons Attribution 4.0 International License. The images or other third party material in this article are included in the article's Creative Commons license, unless indicated otherwise in the credit line; if the material is not included under the Creative Commons license, users will need to obtain permission from the license holder to reproduce the material. To view a copy of this license, visit http://creativecommons.org/licenses/by/4.0/ 